\title{
Accounting for environmental intakes when assessing occupational exposures to uranium
}

\author{
Derek Bingham ${ }^{1, *}$ and Rupert Cockerill ${ }^{1}$ \\ ${ }^{1}$ Dosimetry Service, AWE, Reading, RG7 4PR, UK
}

Identifying occupational exposure to uranium is complicated by the presence of varying amounts of natural uranium found in urine samples due to environmental (dietary) intakes [1]. At AWE, when the total uranium activity in urine in a sample is reported above the investigation level $\left(2.5 \mathrm{mBqd}^{-1}\right)$, then several lines of enquiry are made to determine whether this is of occupational or environmental origin. They include: obtaining a further sample; obtaining information on the person's diet and work history; investigating uranium isotope ratios using alpha and mass spectrometry.

An increase in the number of urine samples with total uranium activity above investigation levels has been observed at AWE in recent years. This appears to be related to the provision on site of a new source of bottled drinking water with a relatively high content of natural uranium. However, it is not always possible to determine with confidence the origin of an elevated uranium in urine result. There can be significant consequences, in terms of the assessed dose, from incorrectly attributing the origin of the exposure.

\section{References}

1. [EURAdOS 2013] Castellani, C. M., Marsh, J. W., Hurtgen, C., Blanchardon, E., Bérard, P., Giussani, A. and Lopez, M. A. IDEAS Guidelines (Version 2) for the Estimation of Committed Doses from Incorporation Monitoring Data. EURADOS Report 2013-01 ISBN 978-3-943701-03-6 (2013).

http://www.eurados.org/ /media/Files/Eurados/documents/EURADOS\%20Report\%20 2013-01\%20online\%20version.pdf?la=en

* Corresponding author: Derek.Bingham@awe.co.uk 